Territorialidades da Cultura Popular na Cidade do Rio de Janeiro

Territorialidades de la cultura popular en la ciudad de Rio de Janeiro

Territorialities of popular culture in the city of Rio de Janeiro Jorge Luiz Barbosa ${ }^{1}$ 


\section{Territorialidades da Cultura Popular na Cidade do Rio de Janeiro}

\section{Introdução}

Considerarmos que a cultura é muito mais do que um conceito normativo empregado para definir distinções entre práticas sociais, ou mesmo para determinar juízos de produção/consumo de bens estéticos. A cultura diz respeito às vivências concretas dos sujeitos no ato de conceber e conhecer o mundo, a partir do reconhecimento de semelhanças e de diferenças que são construídas em seus territórios de existência.

Pode-se afirmar, então, que a cultura é produto do encontro de saberes e fazeres na pluralidade da vida social. Portanto, devemos considerar que a cultura se constrói do movimento próprio das relações dos indivíduos entre si e com a experiência de realização da vida com outros diferentes, promovendo a significação do seu ser-no-mundo individual e coletivo.

$\mathrm{Na}$ mesma direção devemos sublinhar que as culturas urbanas resultam igualmente de cenários da diferença, sendo possível afirmar que a produção e o consumo cultural são próprias às trocas simbólicas em redes de sociabilidade. Todavia, como podemos afirmar a cultura como ato e potência da diferença em espaços socialmente ordenados em hierarquias de consumo de bens simbólicos, geralmemte fundados em arbítrios de superioridade social (e, não raras vezes, racial)?

Para enfrentar o desafio da cultura como expressão da diferença se faz urgente recusar de identidades essencialistas e acabadas, para colocar em destaque o fazer da cultura como um processo inacabado e incompleto do sujeito consigo e com os outros em territorialidades do devir.

\section{Territórios do fazer e territorialidades do devir da cultura}

Partimos da concepção conceitual que a cultura é uma prática significante de apropriação e uso do território. Sob esta angular, o território se nos apresenta como uma relação eminentemente intersubjetiva, constantemente atualizada e reiventada em nossas atuações de compartilhamento no mundo da vida: "o território é o fundamento do trabalho, o lugar da residência, das trocas materiais e espirituais e do exercício da vida" (SANTOS, 2002, p. 10).

No território estão as cristalizações de símbolos, de memórias e de valores que encarnam o sentido da cultura. E, por meio da apropriação do território que se geram os usos e os estilos, combinando maneiras de fazer e invenções de saberes inscritos em posições culturais socialmente construídas. O território emerge como um acervo prático-simbólico, onde tudo pode ser continuamente reconstruído e reordenado das mais diferentes maneiras possíveis.

Nesta perspectiva, não devemos considerar o território como um recorte de chão fechado em si mesmo e com fronteiras absolutamente rígidas ou impermeáveis. O território deve ser percebido e vivido a partir de franjas porosas, por onde as relações de troca de ideias, de valores, de práticas e de objetos se realizam em intensidades diversas. Um universo de abrigos da diferença de vidas socialmente construídas. Ou seja, a construção de uma ordem de proximidades, de afetividades e de conflitos que fazem a cultura 
assumir uma geografia de ações e intenções humanas.

De natureza coletiva de sua construção, a cultura é comunicação entre sujeitos, e destes com territórios socialmente usados. Estamos falando de trocas que tornam os territórios permeáveis à visitação do outro, do diferente e do ignoto. São encontros que conduzem à circularidade de produtos, de práticas e de imaginários que enriquecem as sociabilidades. É justamente para o território que as invenções da cultura ganham sua dimensão prática, vivida, compartilhada; abrindo as possibilidades de sua apropriação como conceito e sua visibilidade como prática social (BARBOSA, 2006).

Ao afirmamos diferentes sujeitos na construção da cultura, estamos colocando em causa as certezas das identidades fixas em territórios estáveis. Reclamamos criticamente outra leitura da identidade (e do território) ao concebê-la como produto de disputas de imaginário no tempo-espaço. Desse modo, defendemos que a identidade tem tanto uma forja histórica, como tem uma pegada espacial². Assim, ao buscarmos a identidade de um território, ou de um lugar na cidade, certamente a encontraremos como intersecção de práticas e que superam a noção de localidade e de comunidade como experiências fixas e essencialistas.

O denominador comum da relação identidade / território é possibilidade permanente das trocas simbólicas e materiais que a produção/ fruição da cultura proporciona. É nesse movimento que os sujeitos se reconhecem e se afirmam como criadores do seu ser-no-mundo. Abordamos, então, a partilha do sensível (RANCIĖRE, 2005) como atributo do uso território, sobretudo como afirma- ção de coletivos e grupos sociais subalternizados na cidade:

A partilha do sensivel faz ver quem pode tomar parte no comum em função daquilo que faz, do tempo e do espaço em que essa atividade se exerce (...). Define-se o fato de ser o visível num espaço comum, dotado de uma palavra comum etc. (RANCIĖRE, 2005, p.16).

Está em causa a visibilidade de sujeitos sociais em espaços compartilhados: territorialidades do devir da construção estética. As territorialidades do devir são produtos da mobilização de táticas e de estratégias de afirmação de pertencimentos culturais que se consolidam a partir do uso do território. Podemos exemplificar com o samba e seus praticantes na notória luta de afirmação sociopolítica da sua estética e, mais recentemente, do funk e do hip hop na superação da criminalização social que ainda enfrentam, tendo como suporte de abrigo as favelas, os subúrbios e as periferias urbanas. É assim que os terreiros, as escolas de samba, os clubes, as quadras, as praças e as esquinas fazem parte do elenco diverso de territorialidades da cultura popular em luta por sua celebração estética e de sua afirmação sociopolítica.

As territorialidades do devir da cultura são ações a contrapelo das hierarquias que se impõem no ato da produção, distribuição e consumo cultural. Estamos diante de um conflito aberto, embora silencioso na cidade. De um lado, emergem as relações horizontais de produção e apropriação da cultura, por meio das quais as fronteiras territoriais tornam-se porosas, portanto permeáveis à comunicação de experiências e à incorporação do diferente em sua legítima presença. E, de outro, as relações verticais, definidas pelo status 
social e pela distância territorial, constituindo indivíduos e coletivos (grupos e classes) exclusivistas de produção e consumo cultural em padrões de não compartilhamento de bens simbólicos (BARTH, 2000, p. 128).

Nesta perspectiva, as territorialidades do devir da cultura emergem como um campo de disputa de imaginários sobre o significado da cidade, traduzindo um enfrentamento ao regime simbólico de hierarquização de sujeitos sociais. Desse modo, são colocadas em destaque as relações de poder entre sujeitos sociais da cultura, e não somente as funções da cultura e/ ou as condições de acesso aos meios de produzir / consumir a cultura em sociedades de desiguais.

\section{A Favela como territorialidade do devir da cultura no desenvolvimento local e urbano}

A negação de territorialidades do devir da cultura retira da cidade a criatividade necessária para inventar o futuro, uma vez que a homogeneização das práticas culturais reduz a convivência e o aprendizado que presença do diferente proporciona. Todavia, as cidades contemporâneas nos colocam diante do desafio de construir reconhecimentos da diferença sociocultural, considerando-a como um valor primordial para a afirmação de sua identidade no mercado simbólico globalizado.

É o caso da cidade do Rio de Janeiro que é celebrada em suas notórias marcações culturais e turísticas, cuja legenda de cidade maravilhosa parece ser sua síntese incontestável (BARBOSA, 2010). Contudo, não há dúvida que as práticas culturais populares têm um papel decisivo na construção dos emblemas imaginários da cidade, sobretu- do os que emergem da pluralidade criativa das favelas.

Embora reúna signos marcadores da cultura carioca, as favelas são ainda consideradas como territórios carentes, miseráveis e violentos. Tais expressões são redutoras da vida social das favelas e, de modo mais incisivo, do não reconhecimento da pluralidade cultural destes territórios populares (BARBOSA; GONÇALVES, 2013).

Apesar dos estigmas da pobreza e da violência que ainda marcam as favelas, é inegável a riqueza de suas expressões estéticas e modos significativos de representar e afirmar a sua diferença cultural. Explica-se este legado das favelas no seu modo de viver a cultura como ação expressivamente relacional, corpórea e intersubjetiva, pois exprimem percursos, memórias, valores inscritos como residência da vida, como compatilhamento do território usado.

Em uma primeira mirada sobre as favelas não identificamos equipamentos de distinção do gosto e do consumo cultural hegemônico. Museus, cinemas, bibliotecas, teatros não ganham destaque na paisagem. Porém, isto não significa que as favelas não sejam lugares de vivências e invenções estéticas. Suas ruas, praças, becos e esquinas transbordam repertórios imagéticos que trazem universos outros do fazer e do viver a cultura.

Então, falamos de territórios de realização práticas criativas. Territórios de cores grafitadas, de sonoridades multiplicadas, de corporeidades bailadas e de memórias figuradas em cenas de identidades em movimento. Ou seja, experiências de construção contínua de relações de intersubjetividade capazes de inventar possibilidades outras de sociabilidade. 


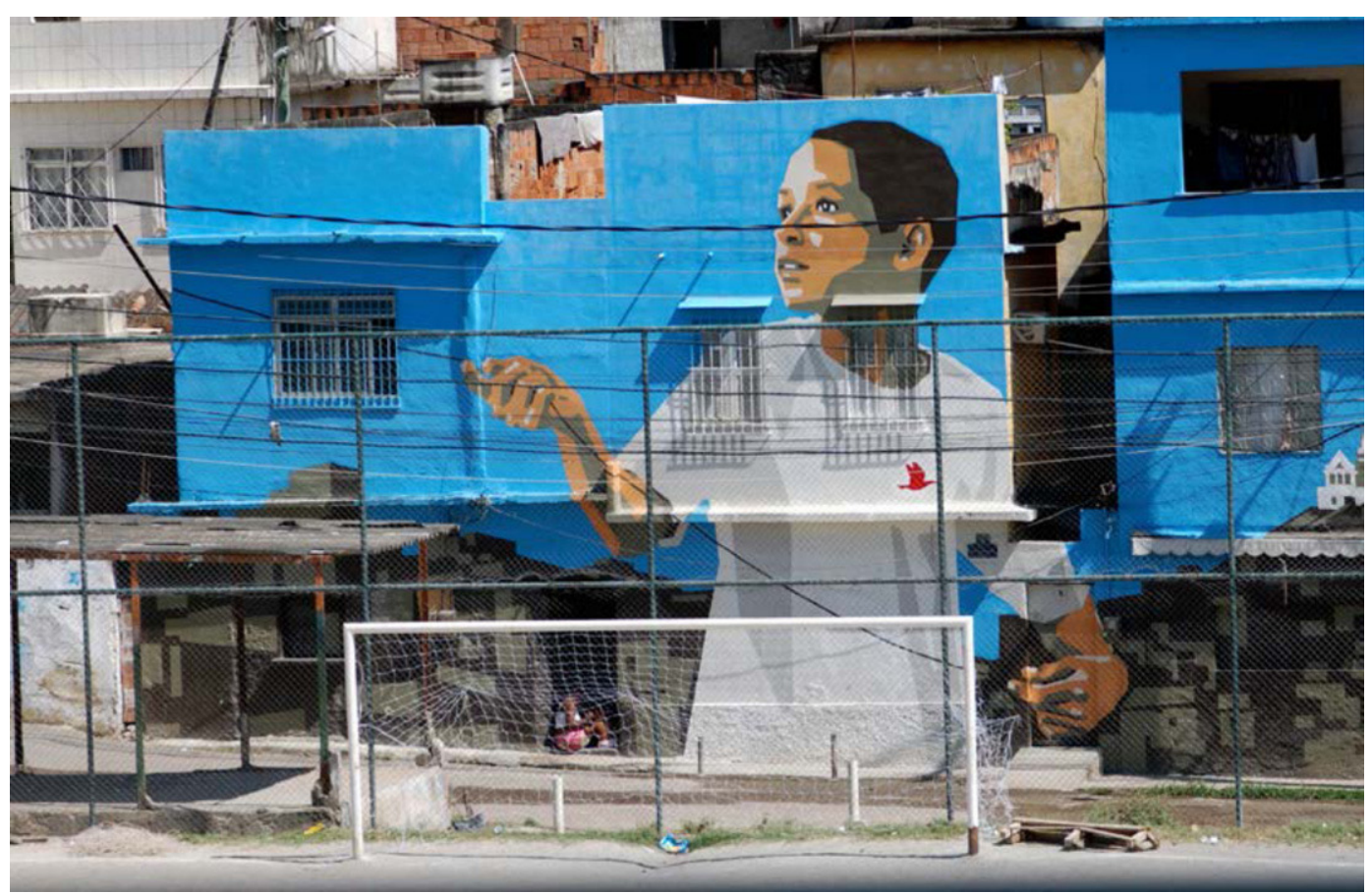

Foto: Davi Marcos (Imagem do Povo - Observatório de Favelas)

O sentido da inventividade estética popular que faz de praças, ruas, becos, muros e escadarias o espaço de representações visuais de desejos, promessas e memórias têm nas favelas o seu recurso e abrigo de socialização. As sonoridades ganham multiplicidades em bares, biroscas, restaurantes e clubes para se tornarem cenas de samba, forró, rock, hip hop, charme e funk. As lajes se tornam coberturas para os sabores da feijoada na roda de pagode ou, então, tablados para encenação de peças teatrais e exibição de filmes. De um lado da calçada, os salões de beleza esculpem penteados afros para afirmação de pertencimentos. E, de outro, as lan houses, barracas de camelôs e biroscas se tornam iconografias desafiadoras de temporalidades diferenciais. Enquanto tudo isso acontece (...) celulares, ipads, iphones e tabletes sintonizam as favelas com a velocidade global. São encontros, percursos e táticas que habitam um mesmo território de pertenças na complexidade da vida urbana. Há, portanto, um catálogo vívido de múltiplas linguagens, estilos, tradições e inovações nas favelas como riqueza cultural da própria cidade, embora sejam notoriamente desprovidas de equipamentos públicos de qualidade.

O mercado de consumo urbano entra com voracidade nas favelas, prometendo a felicidade com seus objetos de prestígio social. Descoberta pelo mercado de consumo, a favela hoje é reconhecidamente um território de consumidores de classes $C$ e $D$ de distintas empresas para expansão de vendas de mercadorias mais sofisticadas (bens eletrônicos, roupas e calçados de marcas, cervejas artesanais e cremes naturais) e não só as vinculadas ao consumo imediato ${ }^{3}$.

A própria imagem da favela se tornou um produto de consumo para o turismo internacional de aventuras 
e até mesmo para emprestar ambiência de realidade às produções cinematográficas e televisivas ${ }^{4}$. E, como lócus privilegiado da invenção da cultura popular, a favela é muitas vezes tratada como celeiro de talentos (descartáveis) e fonte de culturas extraordinárias (versão atualizada do exótico). Estereotipias da lógica consumista do mercado que buscam incessantemente retirar dos territórios populares o intangível - ou seja, as seus pertencimentos simbólicos - e transformá-los em commoditys espetaculares de consumo.

Curiosamente, os objetos e as imagens de consumo são muitas vezes traídos em suas finalidades mercantis objetivadas nas favelas, sobretudo quando retraduzidos e reinventados em seus usos. O celular é tomado como dispositivo de produção estética de autorepresentação visual e sonora por parte dos jovens. Os computadores são mobilizados como instrumentos de comunicação entre os jovens (notadamente por meio de facebook, istagram, chats) ${ }^{5}$. Onde 0 sentido único parece se instaurar, se observa a transformação em dobraduras de apropriações e, não raramente, em processos de mobilização de atos e linguagens afirmativas de pertencimentos ao território e de novas posições de sujeitos na cena cultural urbana. Estamos diante de um jogo de disposições complexas entre o mercado de produção e consumo de signos culturais, tendo em seus rebatimentos territoriais de recepção criativa uma possibilidade de afirmação das narrativas de si como disputa no imaginário urbano.

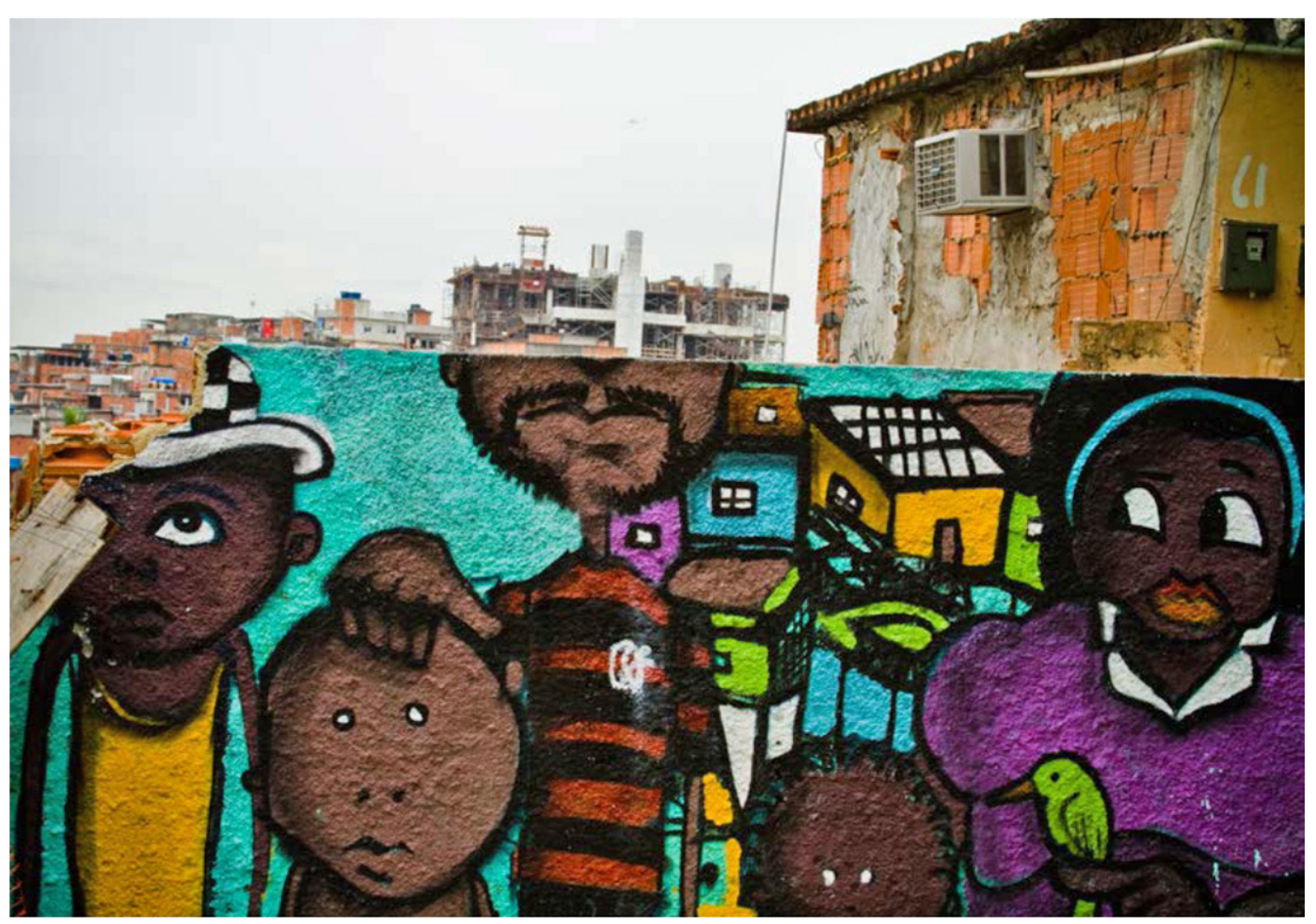

Foto: Francisco Cesar (Imagem do Povo - Observatório de Favelas) 
Apesar da pluralidade de seus modos narrativos e de formas inovadoras de suas interpretações, os criadores de cultura das favelas enfrentam desafios permanentes para sua afirmação na cena estética urbana, incluindo a profunda desigualdade da repartição de financiamento da produção e comunicação das ações de indivíduos, grupos e instituições dedicadas à arte à cultura. Até mesmo quando se trata da democracia competitiva dos editais públicos do Estado e/ou da responsabilidade social de empresas, há limitações significativas para participação dos coletivos e indivíduos que fazem a cultura nas favelas, desde a falta de alvará para funcionamento da atividade ou mesmo de certidões que atestem a existência das práticas artísticas.

Entretanto, é importante sublinhar a multiplicidade de linguagens de criação estética presentes nas favelas. A música e a dança em seus diferentes estilos e tradições se combinam com a apropriação de novas tecnologias e novos instrumentos digitais de produção simbólica (câmeras fotográficas, filmadoras, tabletes e celulares). Esse encontro constroem territorialidades do devir da cultura para ampliação de repertórios estéticos para além das experimentações já dadas em favelas, constituindo uma nova modalidade de produção de representações, sonoridades, narrativas e visualidades na cena cultural das favelas e da própria da cidade.

Os diferentes repertórios se entrelaçam em espaços de fruição notadamente coletivos e comuns. São os espaços de sociabilidade como praças, ruas, quadras esportivas, bares, salões de festas de igrejas, escolas e lan houses que desabrocham como o principal recurso para o compartilhamento de experiências artísticas nas favelas. A rara presença de equipamentos de arte e cultura públicos e/ou privados em favelas, associada à baixa mobilidade de seus jovens e adultos na cidade, fazem com que os grupos culturais inventem modos de apropriação de territórios em sua dimensão pública.

É na partilha sensível do território em sua dimensão pública é que se reafirmam tradições na construção de cenas culturais amplamente inseridas no cotidiano dos moradores, assim como das novas mediações técnicas e simbólicas que afirmam pertenças territoriais ${ }^{6}$. Há, portanto, uma aprofunda diferença entre o que definimos como fruição estética compartilhada, presente nas favelas, e o consumo individual de bens culturais distintivos nos espaços formais da cidade. Na verdade, as práticas culturais aludidas se revelam como processos e formas de visibilidade de significados, posições e territórios que os grupos sociais ocupam e compartilham suas existências numa cidades de desiguais.

As territorialidades da cultura nas favelas não se configuram como uma recusa radical ou resistência genuína ao neoliberalismo que domina a produção e o consumo cultural na cidade. Estas estão para além das simplificações ideológicas e/ou românticas de luta contra o capitalismo, uma vez que significam um modo de produção da cultura que se afirma pela existência de pertencimentos ao território, porém com investimentos em relações mais amplas de comunicação com o conjunto da cidade. Revistas, programas de televisão e rádio, milhares de cd`s comercializados; romances e poesias ganhando mercados editoriais; produção audiovisual arrebatando prêmios nacionais e internacionais; clipes do passinho do menor com milhares de visualizações no You Tube; bailes de funk, de charme e forró atraindo diferen- 
tes galeras; e batalhas de hip hop mobilizando seus rappers e bailarinos de rua - são expressões contundentes de uma cultura de massas que nascem, mas transbordam as favelas, em misturas de alegrias, dramas, recusas, paixões e protestos que assumem perspectivas outras de apropriação estética do/no espaço urbano. Reside nesta cartografia de ações um conjunto de oportunidades reais para desenvolvimento econômico e social nas escalas local e urbana.

A destacada criatividade permite projetar uma um promissor desenvolvimento local em bases efetivamente comunitárias, com enlaces de uma economia de compartilhamentos de produção, comunicação e fruição estética. Para tanto, se faz necessária à formulação e à implementação de políticas culturais de investimentos em redes colaborativas - envolvendo indivíduos, grupos e coletivos que atuam nos territórios populares - justamente as que visam garantir as condições materiais do fazer e a visibilidade de suas realizações.

É imperiosa a publicização dos recursos de financiamento do Estado, considerando a produção cultural e artística como parte integrante e integradora da vida social nas favelas. Os investimentos públicos no âmbito da cultura deverão estar orientados para o afeiçoamento ao território usado pelos praticantes da cultura. Ou seja, reconhecer as práticas culturais e artísticas como ato de sujeitos e potência de sociabilidades inovadoras.

Não se preconiza aqui, evidentemente, uma economia de espetáculos que certamente fará das favelas um objeto de consumo de classes médias esclarecidas e ardorosas de entretenimento cultural. Mas uma virtualidade de empoderamento da criação e da fruição estética em curso nas favelas.

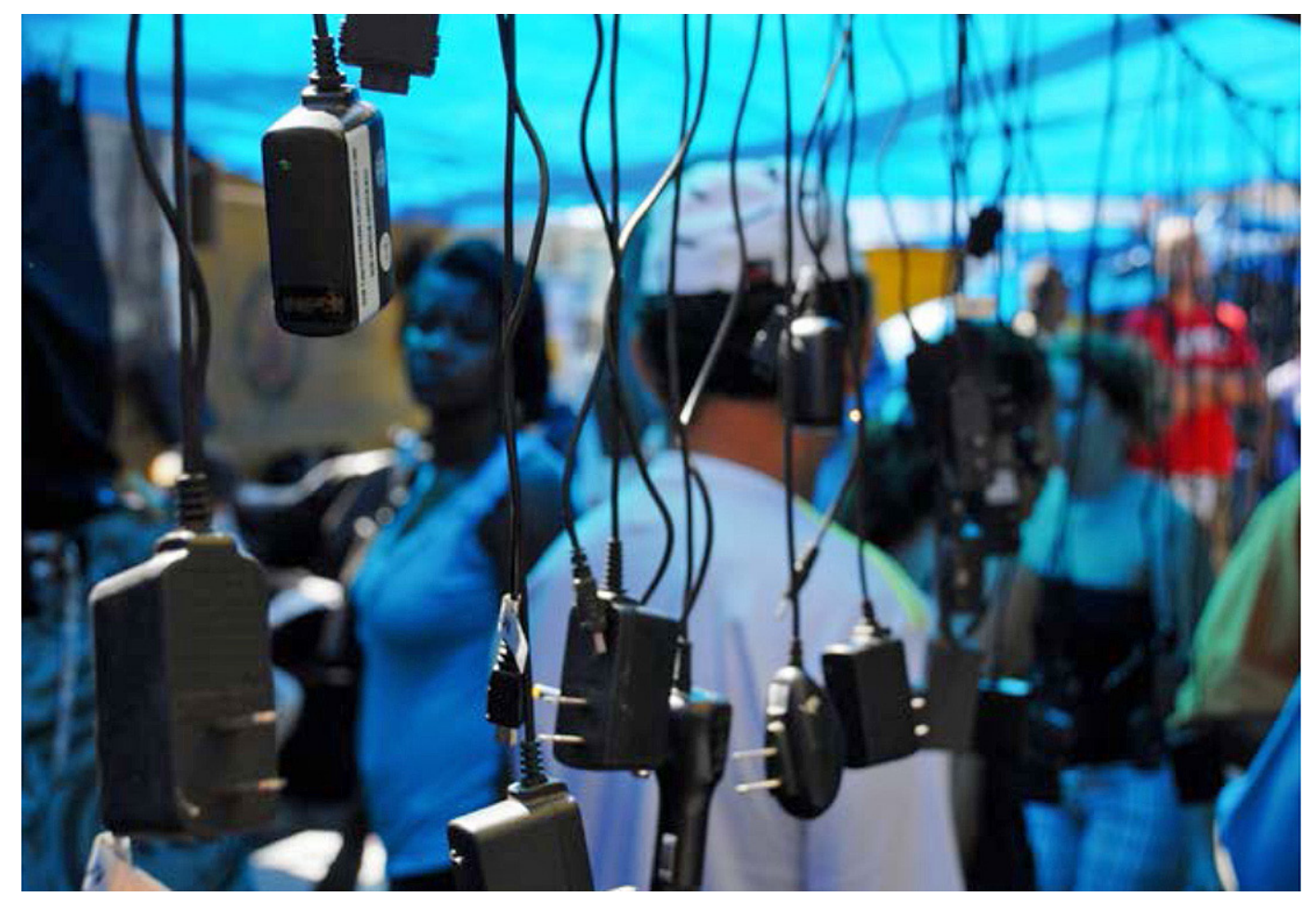

Foto: Naldinho Lourenço (Imagem do Povo - Observatório de Favelas) 


\section{Considerações finais}

A cultura é o habitar em uma obra inconclusa, sobretudo porque a criação cultural é um ato de trocas simbólicas, corpóreas e materiais entre os seres humanos. Assim, criamos vínculos e interpretamos nossa presença na sociedade. Nesta perspectiva, a criação cultural deve ser vivenciada como um processo que visa não somente gerar obras, mas também inventar as possibilidades de sua recepção, por meio da mobilização de práticas estéticas e a difusão de repertórios artísticos. Trata-se, portanto, do empenho da construção de sujeitos para ação/fruição estética e não de plateias consumidoras para objetos/espetáculos. Abre-se daí a senda para estabelecer nexos entre a cultura e a democratização da cidade, tendo no território a sua necessária mediação.

È preciso reconhecer, portanto, que as favelas são territórios de reinvenção permanente da cultura urbana. Isto significa valorizar a diferença como matriz de nossa formação cultural, sobretudo ao promover encontros entre distantes e próximos como possibilidade do respeito à alteridade e da tessitura de acontecimentos artístico-culturais como mediações para sociabilidades transformadoras.

As experiências culturais em favelas devem ser referências decisivas para políticas publicas de democratização da fruição estética urbana, sobretudo porque enfatizam o protagonismo de jovens na intervenção cultural e artística no território, assim como valorizam a dimensão pública do estar-com-o-outro.

A cultura é patrimônio materialmente inscrito. Mas é também conhecimento de nós mesmos. Um sentido de pertencer a algo que nos pertence: o território. Uma morada virtual (no sentido de vida) que nos faz ser/estar como a expressão diferenciada de significados. Porém, a cultu- ra também nos permite interrogar sobre a nossa posição, sobre o nosso território de existência, sobre a nossa experiência no/ do mundo; porque está imersa em nossas práticas e condutas sociais.

As territorialidades do devir da cultura se revelam como a construção de um campo para as disputas de imaginário sobre o sentido do mundo, compreendendo o imaginário como a força de evocação de imagens (visuais, sonoras, olfativas e gustativas) com a qual travamos nossas lutas simbólicas para legitimar uma posição e uma existência, justificar uma origem, definir trajetos e, sobretudo, iluminar as possibilidades do devir.

Nas favelas, as práticas culturais institucionalizadas ou não, individuais ou coletivas, autônomas ou vinculadas a grupos, são modos plurais de manifestação de sujeitos concretos, que visam significar suas vidas e suas formas de lidar com o cotidiano. São, na sua complexa composição, estéticas de atitude política que se revelam como referências fundamentais para as disputas de imaginário sobre o sentido da cultura e da própria cidade.

\section{Bibliografia}

BARTH, F. A análise da cultura em sociedades complexas. Rio de Janeiro: Contra Capa, 2000.

BARBOSA, J. L. Considerações sobre a relação cultura, território e identidade. In: GUELMAN, L. (org.). Interculturalidades. Niterói, RJ: EDUFF, 2006.

BARBOSA, J. L. Paisagens da natureza, lugares da sociedade: a construção imaginária do Rio de Janeiro como cidade maravilhosa. Revista Biblos 3W, Barcelona: Uni- 
versidade de Barcelona, Vol. XV, n 865,25 de marzo de 2010.

BARBOSA, J. L. ; DIAS, C. G. (org). Solos Culturais. Rio de Janeiro: Secretaria de Estado de Cultura do Rio de Janeiro / Petrobras/ Observatório de Favelas, 2013.

BONNEMAISON, J. ; CAMBRÉZY, L. Le lien territorial: entre frontiéres et identités. Géographies et Cultures $\mathrm{n}^{\circ} 20$, Paris, L'Harmattan, 1986.

CLAVAL, P. A Geografia Cultural. Florianópolis: Ed. da UFSC, 1999.

GEERTZ, C. A interpretação das culturas. Rio de Janeiro: Ed. Guanabara, 1989.

MARTIN, D. C. Identités e politique: récit, mythe et ideologie. Paris: PFNSP, 1994.

RANCIĖRE, J. A partilha do sensível. São Paulo: EXO experimental org. ; Ed. 34, 2005.

SANTOS, M. A Natureza do Espaço. São Paulo: EDUSP, 2002.

SILVA, J. S. ; BARBOSA, J. L. ; FAUSTINI, M. V. O Novo Carioca. Rio de Janeiro: Mórula, 2012.

WILLIAMS, R. Cultura. São Paulo: Editora Paz e Terra, 1992.
1 Professor Associado do Departamento de Geografia e Diretor do Observatório de Favelas do Rio de Janeiro. Contato: jorgebarbosa@vm.uff.br

2 Para pegada espacial nos referimos às condições de apropriação demarcadora (efêmera ou duradoura) de territórios por parte de grupos e coletivos sociais.

3 Diversas empresas definem táticas de marketing e de vendas para os moradores de favelas. Empresas de bens eletrônicos sofisticados (televisores, computadores, tabletes, celulares) e empresas de cosméticos (incluindo os cremes, shampoos, maquiagem para negras e negros).

4 Filmes comerciais (vide Cidade de Deus e Tropa de Elite I e II), novelas e programas de televisão ganharam repercussão nacional e internacional e, é claro, muito dinheiro ao encenar a vida das favelas, sobretudo os que colocaram a violência urbana em destaque.

5 A apropriação e uso de tecnologias de informação e comunicação afirmam a visibilidade do jovem de origem popular, geralmente estigmatizado e desconhecido na cidade. Esse processo significa, por outro lado, uma possibilidade formidável de ampliação de sua experiência de tempo/espaço, uma vez que sua mobilidade urbana é reduzida e constrangida por situações econômicas, sociais e raciais (BARBOSA; DIAS, 2013).

6 As mediações simbólicas expressam modos de representações da realidade, resultantes do complexo processo pelo qual os significados são produzidos e comunicados entre pessoas de um mesmo grupo cultural (HALL, 1992). 